\title{
Determinants of complex regional pain syndrome type I in patients with scaphoid waist fracture- a multicenter prospective observational study
}

\author{
Hao Gong ${ }^{1,2}$, Gang Zhao', Yuzhou Liu and Zhengfeng Lu*
}

\begin{abstract}
Background: The aim of this prospective study was to assess the incidence of complex regional pain syndrome type I (CRPS I) in patients with scaphoid waist fracture and to explore associated factors.

Methods: This was a multicenter, prospective observational study. Demographic, imaging indicators and clinical data were collected before the conservative treatment of scaphoid waist fracture patients. The occurrence of CRPS I and pain condition were the main outcomes. To explore the factors associated with CRPS I, multivariate logistic regression model was used.

Results: A total of 493 scaphoid waist fracture participants undergoing conservative treatment were recruited for this study. The incidence of CRPS I was 20\% $(n=87)$. The average time between injury and the onset of CRPS I was $6.7 \pm 2.1$ weeks. Multivariable logistic regression analysis revealed that female sex (odds ratio (OR): 1.669; 95\% confidence interval (CI): 1.189-2.338), diabetes mellitus (OR: 3.206; 95\% Cl: 2.284-4.492), and severe pain condition before treatment (visual analog scale (VAS) score more than $4 \mathrm{~cm})(\mathrm{OR}: 27.966 ; 95 \% \mathrm{Cl}:$ 19.924-39.187) were independently associated with CRPS I.

Conclusions: Patients suffering from scaphoid waist fracture may be at a higher risk of CRPS I, especially in women with diabetes mellitus who report severe pain before treatment. Early screening and regular follow up evaluation are recommended in these patients.
\end{abstract}

Keywords: Scaphoid waist fracture, Complex regional pain syndrome type I, Pain, Risk factors

\section{Background}

Complex regional pain syndrome type I is a chronic pain condition, which characterized by spontaneous abnormal pain intensity and duration. In two population-based studies performed in North America [1] and Europe [2], the incidence of CRPS I was 5.5 and 26.2 per 100,000 person-years, respectively. The common symptoms of

*Correspondence: zhengfenglu@email.poe.edu.pl

${ }^{1}$ Department of Hand Surgery, Wuxi Ninth People's Hospital, Wuxi, Jiangsu, China

Full list of author information is available at the end of the article
CRPS I include abnormal sensation, vasomotor edema changes, and motor dysfunction [3]. The clinical signs include four categories: the evidence of sensory; vasomotor; edema and trophic. The diagnosis of CRPS I involves the presence of at least two clinical signs included in the four categories and at least three symptoms in its four categories [4]. Previous studies [5] reported that trauma was the most common events of CRPS I and the athletes can be easily affected by CRPS I because of exposure to traumatic or overuse injuries [6]. The causes of CRPS I are unclear. Evans et.al [4] reported that an excess of original author(s) and the source, provide a link to the Creative Commons licence, and indicate if changes were made. The images or other third party material in this article are included in the article's Creative Commons licence, unless indicated otherwise in a credit line to the material. If material is not included in the article's Creative Commons licence and your intended use is not permitted by statutory regulation or exceeds the permitted use, you will need to obtain permission directly from the copyright holder. To view a copy of this licence, visit http://creativecommons.org/licenses/by/4.0/. The Creative Commons Public Domain Dedication waiver (http://creativecommons.org/publicdomain/zero/1.0/) applies to the data made available in this article, unless otherwise stated in a credit line to the data. 
afferential input related to the damaged tissue could start a chain of activation involving sympathetic neurons. The activity of sympathetic postganglionic fibers could produce spasms of the arteries and therefore ischemia with increased capillary filtration pressure, edema and swelling. Generally speaking, comprehensive approach maybe more suitable for CRPS I, including pharmacological therapy, physical therapy, therapeutic exercise, and neurorehabilitation, psychological and educational interventions [4]. The timing of the pharmacological intervention is important for treatment outcomes. Prednisolone might be useful for the treatment of CRPS and vitamin C could work as a preventive strategy [7].

According to the authors' clinical experience, CRPS I may develop after scaphoid fractures, which was also be reported in previous studies [8-10]. Distal radius fracture was the most common induced event of CRPS I and it was also the most commonly encountered associated injury of scaphoid fracture [11]. However, few studies have focused on the incidence of CRPS I in scaphoid fractures patients, most articles mainly focus on the wrist fracture, which was includes multiple fracture types [10]. In addition, exploring the risk factors for CRPS I is important, which helps clinicians establish prevention measures and alleviate the discomfort of patients.

The aim of the study was to assess the incidence of CRPS I in patients with scaphoid waist fractures and to explore the associated factors.

\section{Methods}

\section{Study design}

This was a multicenter, prospective observational study that was approved by the ethics board of the four participating institutions. Signed informed consent was obtained from all patients.

\section{Patients}

The baseline data were collected before conservative treatment, and included demographic and imaging indicators and clinical data. The demographic data included age, sex, dominant hand, injured side, body mass index, education, job status, socioeconomic status, days between injury and casting, type of trauma, fracture type, current tobacco use, and diseases, including hypertension and diabetes mellitus. According to the image data, imaging indicators were measured at each participle, which included the maximum displacement, scapholunate angle, radiolunate angle, carpal height index ratio, and lateral intrascaphoid angle [12].

From August 2016 to November 2019, scaphoid waist fracture patients were recruited from the orthopedics department of four level I trauma centers in China. Scaphoid waist fracture is primarily diagnosed by imaging studies, including radiographs and CT scans. The radiograph exam included five radiographic views: posterior-anterior, lateral, semisupine, semiprone, and elongated scaphoid. All imaging data were collected by different recruiting sites and assessed by the same team, which included one senior radiologist (GZ) and one senior orthopedic doctor $(\mathrm{GH})$. Convenient sampling was used as a sampling method. All patients received standard conservative treatment pathway, which includes cast immobilization, patient education and rehabilitation training [13]. The wrist was cast using the below-elbow cast without inclusion of the thumb in neutral alignment for 10 weeks.

The following inclusion criteria were used: (1) Bicortical scaphoid waist fractures, which were defined as a break in the continuity of both cortices on any radiographic view [14]; (2) nondisplaced or minimally displaced fracture, which was defined as less than $1 \mathrm{~mm}$ of gapping or translation between fracture fragments on CT or on any of five radiographic views; (3) The time from injury to hospital patients was less than 2 weeks; and (4) patients underwent conservative treatment. The exclusion criteria were as follows: (1) patients who received surgical treatment; (2) patients with concomitant injuries of the upper limb; (3) age $\leq 18$ years; (4) patients with a history of CRPS I and other chronic pain conditions because these patients have a higher incidence of recurrence [15]; (5) patients who refused to participate in the study; (6) during the treatment, patients suffer complications, such as delayed- or nonunion, and other conditions require secondary intervention; and (7) pregnant and lactating women.

\section{Primary outcome measures}

The primary outcome of this study was the occurrence of CRPS I. The patients were followed-up every week during the period of cast immobilization and the first 3 months after cast removal and at the 6-, 9- and 12-month followups. A $10 \mathrm{~cm}$ VAS scale $(0=$ no pain, $10=$ total pain $)$ was used by a pain specialist (YL) at each follow-up to assess the patient's pain level. Few scaphoid waist fracture patients reported greater pain $(V A S>4 \mathrm{~cm}$ ) within 1 year after treatment in previous studies [16, 17]. Therefore, $4 \mathrm{~cm}$ was defined as the cutoff score of this study. For patients who present disproportionate pain in the operated limb, we initially attempted to exclude other potential causes, and then we made the diagnosis of CRPS I according to Budapest criteria [18]. The specific process is shown in Fig. 1.

\section{Data collection techniques}

The clinical data included pain condition, wrist function, quality of life, psychological condition, and radiological 


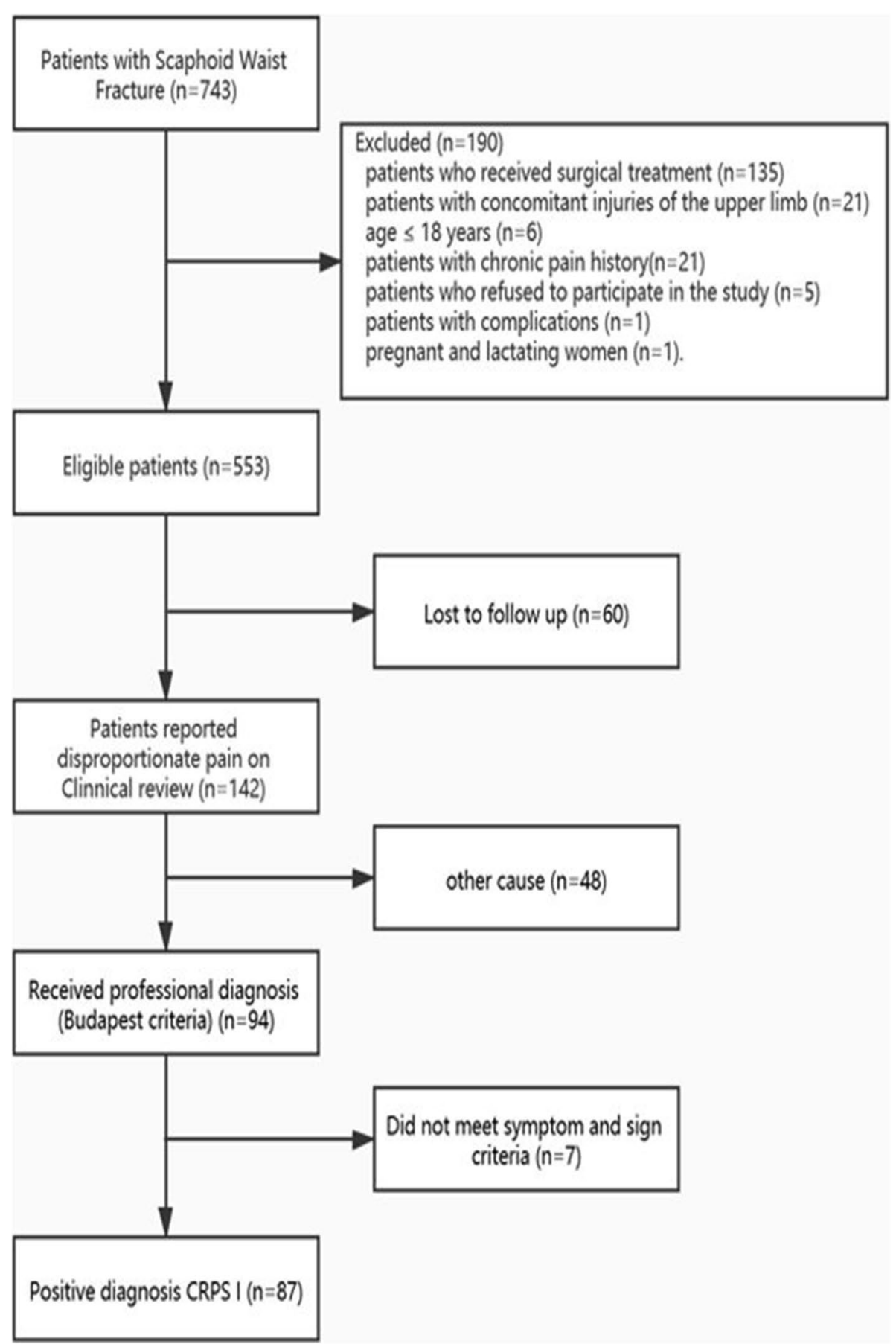

Fig. 1 Flow chart of patient inclusion in the present study

measurements. Baseline pain condition was also assessed using the VAS. A dynamometer (Zhengyi Company, Tianjin, China) was used to measure the wrist function, including the range of motion and grip strength. The ranges of motion include flexion, extension, pronation, supination, ulnar deviation and radial deviation. The grip strength is presented as the percentage compared to the healthy side. We also assessed wrist function using the Quick Disabilities of the Arm, Shoulder, and Hand (QuickDASH) questionnaire [19, 20] $(0=$ no disability, and $100=$ total disability). The patient-rated wrist evaluation score (PRWE) score was used to calculate the wrist 
pain and disability, and contained 3 parts and 15 items $(0=$ no disability and $100=$ maximum loss of function and marked pain). The Mayo modified wrist score was calculated preoperatively in each patient [21]. The Chinese version of the Short-Form Health Survey (SF-12) was used to evaluate quality of life [22]. The patient's psychological conditions were evaluated using the Hospital Anxiety and Depression Scale (HADS) (21 items) [23], which included two subscales (anxiety and depression) and 14 questions. Eight points were defined as the cutoff scores of depression and anxiety, which divided the patients in to abnormal cases and normal cases.

\section{Statistical analyses}

We determined the sample size according to the number of variables. The lower limit of the number of included individuals was at least 10 times the number of events per variable [24]. In this study, 32 variables were included in multivariate analysis. Therefore, 320 patients were required to be enrolled in the study. Considering a possible dropout of $20 \%$, the recruitment target was 88 participants.

Statistical analyses were performed using Statistical Package for the Social Sciences (SPSS, version 25, Chicago, IL). All reported $P$-values were two-tailed. Fisher's exact test and t-test were conducted as univariate logistic regression analyses. Variables with statistically significant results $(P<0.1)$ in univariate analysis were included in multivariate analysis (Backword-Wald) to identify the variables that were independently associated with CRPS I. The results were expressed as ORs and 95\% CIs. Differences were considered statistically significant at $p<0.05$.

\section{Results}

A total of 743 participants were screened for eligibility, of whom 190 (33.6\%) patients were excluded. 553 participants were recruited in this study. A total of 493 (89\%) patients, including 295 male and 198 female patients, completed the 1-year follow-up. The mean age was $50.3 \pm 4.2$ years. The mean time interval from injury to conservative treatment was 3 days. The average time between injury and the onset of CRPS I was $6.7 \pm 2.1$ weeks. In this study, the results of the Budapest criteria demonstrated that $87(20 \%)$ patients presented with CRPS I.

The demographic and clinical characteristics are summarized in Tables 1 and 2. The factors associated with CRPS I were gender $(p=0.031)$, type of trauma $(p=0.035)$, diabetes mellitus $(p=0.005)$, pain condition before treatment $(p=0.001)$, anxiety $(p<0.001)$, SF-12 mental points $(p<0.001)$, and PRWE pain points $(p=0.003)$. These parameters were included
Table 1 Demographic characteristics of study sample

\begin{tabular}{|c|c|c|c|}
\hline Characteristics & $\begin{array}{l}\text { Patients With } \\
\text { CRPS I }(n=87)\end{array}$ & $\begin{array}{l}\text { Patients Without } \\
\text { CRPS I }(n=406)\end{array}$ & $P$ \\
\hline Age (year) & $51.5 \pm 19.2$ & $49.7 \pm 18.8$ & 0.420 \\
\hline \multicolumn{4}{|l|}{ Gender, n (\%) } \\
\hline Male & $61(70)$ & $234(58)$ & \\
\hline Female & $26(30)$ & $172(42)$ & $0.031^{*}$ \\
\hline \multicolumn{4}{|l|}{ Dominant hand, n (\%) } \\
\hline Left & $8(9)$ & $44(11)$ & \\
\hline Right & $79(91)$ & $362(89)$ & 0.651 \\
\hline \multicolumn{4}{|l|}{ Injured side } \\
\hline Dominant & $74(85)$ & $348(86)$ & \\
\hline Non-dominant & $13(15)$ & $58(14)$ & 0.874 \\
\hline Body Mass Index $\left(\mathrm{kg} / \mathrm{m}^{2}\right)$ & $20.7 \pm 2.9$ & $20.4 \pm 3.0$ & 0.395 \\
\hline \multicolumn{4}{|c|}{ Education, $\mathrm{n}(\%)$} \\
\hline University & $55(64)$ & $288(71)$ & \\
\hline Primary and middle & $30(34)$ & $112(28)$ & \\
\hline Illiterate & $2(2)$ & $6(1)$ & 0.351 \\
\hline \multicolumn{4}{|l|}{ Job status, n (\%) } \\
\hline Unemployed & $23(26)$ & $102(25)$ & \\
\hline Employed & $64(74)$ & $304(80)$ & 0.798 \\
\hline \multicolumn{4}{|c|}{ Socioeconomic status, n (\%) } \\
\hline High & $19(22)$ & $75(18)$ & \\
\hline Medium & $61(70)$ & $287(71)$ & \\
\hline Low & $7(8)$ & $44(11)$ & 0.616 \\
\hline $\begin{array}{l}\text { Time from injure to } \\
\text { casting }\end{array}$ & $3.1 \pm 0.8$ & $3.0 \pm 1.1$ & 0.422 \\
\hline \multicolumn{4}{|l|}{ Type of trauma, $n$ (\%) } \\
\hline Twisting & $5(6)$ & $36(9)$ & \\
\hline Fall & $42(48)$ & $284(70)$ & \\
\hline Punch & $20(23)$ & $46(11)$ & \\
\hline MVA & $12(14)$ & $42(10)$ & \\
\hline Uncertain & $8(9)$ & $18(4)$ & $0.002^{*}$ \\
\hline \multicolumn{4}{|l|}{ Fracture type, n (\%) } \\
\hline Waist & $78(90)$ & $363(89)$ & \\
\hline Distal & $9(10)$ & $43(11)$ & 0.946 \\
\hline $\begin{array}{l}\text { Current tobacco use, } \\
\text { n (\%) }\end{array}$ & $25(29)$ & $118(29)$ & 0.904 \\
\hline \multicolumn{4}{|l|}{ Diseases } \\
\hline Hypertension, n (\%) & $19(22)$ & $91(22)$ & 0.907 \\
\hline $\begin{array}{l}\text { Diabetes mellitus, } \\
\text { n (\%) }\end{array}$ & $15(17)$ & $` 132(33)$ & $0.005^{*}$ \\
\hline
\end{tabular}

*P $P<0.05$

in multivariable logistic analysis to identify the independently associated factors of developing CRPS I in scaphoid waist fracture. Female sex (OR: 1.669; 95\% CI: 1.189-2.338), diabetes mellitus (OR: 3.206; 95\% CI: 2.284-4.492), severe pain condition before treatment (VAS more than 4cm) (OR: 27.966; 95\% CI: $2.323-$ 6.151) were independently associated with CRPS I (Table 3). 
Table 2 Clinical characteristics of study sample

\begin{tabular}{|c|c|c|c|}
\hline Characteristics & Patients with CRPS I $(n=87)$ & $\begin{array}{l}\text { Patients without CRPS I } \\
(n=406)\end{array}$ & $P$ \\
\hline Pain condition before treatment (VAS, $\mathrm{cm}$ ) & $6.2 \pm 16.5$ & $5.7 \pm 1.3$ & $0.001^{*}$ \\
\hline Grip strength $(\mathbf{k g})$ & $37.2 \pm 18.4$ & $39.5 \pm 16.9$ & 0.257 \\
\hline Grip strength (\% value on healthy side) & $65 \%$ (50 to 69$)$ & $61(52$ to 64$)$ & 0.162 \\
\hline Quick DASH (points) & $74.1 \pm 1.9$ & $74.6 \pm 2.3$ & 0.059 \\
\hline Maximum displacement (mm) & $1.1 \pm 0.6$ & $1.2 \pm 0.4$ & 0.056 \\
\hline Mayo Modified Wrist Score (points) & $87.6 \pm 18.2$ & $91.5 \pm 17.6$ & 0.063 \\
\hline \multicolumn{4}{|l|}{ Wrist range of motion $\left(^{\circ}\right)$} \\
\hline Flexion & $78.2 \pm 19.3$ & $77.8 \pm 18.5$ & 0.856 \\
\hline Extension & $81.4 \pm 12.3$ & $80.4 \pm 12.7$ & 0.103 \\
\hline Pronation & $80.2 \pm 17.5$ & $80.8 \pm 16.7$ & 0.763 \\
\hline Supination & $86.5 \pm 12.9$ & $85.4 \pm 11.2$ & 0.419 \\
\hline Ulnar deviation & $32.1 \pm 8.2$ & $31.9 \pm 7.8$ & 0.830 \\
\hline Radial deviation & $18.8 \pm 5.7$ & $19.3 \pm 6.5$ & 0.507 \\
\hline \multicolumn{4}{|l|}{ HADS (points) } \\
\hline Depression & $7.4 \pm 3.1$ & $6.9 \pm 2.5$ & 0.106 \\
\hline Anxiety & $7.1 \pm 3.8$ & $6.0 \pm 2.2$ & $<0.001^{*}$ \\
\hline \multicolumn{4}{|l|}{ SF-12 (points) } \\
\hline Physical & $48.4 \pm 3.6$ & $49.1 \pm 7.2$ & 0.378 \\
\hline Mental & $42.9 \pm 4.3$ & $43.4 \pm 4.8$ & $<0.001^{*}$ \\
\hline Mayo Modified Wrist Score (points) & $87.1 \pm 18.9$ & $86.8 \pm 16.3$ & 0.880 \\
\hline \multicolumn{4}{|l|}{ Radiographic measures $\left(^{\circ}\right)$} \\
\hline Scapholunate angle & $81^{\circ}\left(71\right.$ to $\left.87^{\circ}\right)$ & $81^{\circ}\left(67\right.$ to $\left.88^{\circ}\right)$ & 0.342 \\
\hline Radiolunate angle & $29^{\circ}\left(22\right.$ to $\left.33^{\circ}\right)$ & $30^{\circ}\left(23\right.$ to $\left.30^{\circ}\right)$ & 0.416 \\
\hline Carpal height index & 0.45 (0.43 to 0.50$)$ & 0.44 (0.42 to 0.50$)$ & 0.234 \\
\hline Lateral intrascaphoid angle & $68^{\circ}\left(59\right.$ to $\left.74^{\circ}\right)$ & $68^{\circ}\left(60^{\circ}\right.$ to $\left.74^{\circ}\right)$ & 0.146 \\
\hline \multicolumn{4}{|l|}{ PRWE (points) } \\
\hline Pain & $19.3 \pm 1.3$ & $18.9 \pm 1.4$ & $0.003^{*}$ \\
\hline Function & $16.7 \pm 2.3$ & $17.1 \pm 1.7$ & 0.063 \\
\hline Total & $35.1 \pm 2.1$ & $34.9 \pm 2.5$ & 0.487 \\
\hline
\end{tabular}

VAS 100-mm visual analogue scale, Quick DASH Quick Disabilities of the Arm, Shoulder, and Hand, PRWE Patient-rated wrist evaluation score

Non-dominant hand values increased by $5 \%$

${ }^{*} P<0.05$

\section{Discussion}

Scaphoid fracture is a frequent and common carpal fracture and accounts for 2 to $7 \%$ of all fractures [13]. Young people are the most affected population [13]. However, chronic pain conditions may occur after the treatment, which could potentially disable patients for an extended time. Chronic pain conditions may be caused by some surgical factors, such as nonunion and malunion, but in most chronic pain cases no obvious cause can be found. The presence of CRPS I is one of the major underlying causes of chronic pain conditions [25].

In total, 438 patients were recruited consecutively and completed the 1-year follow-up. The incidence of CRPS I in this study was $20 \%$, which is lower than that in distal radius fracture patients (32.2\%) [26]. The disparity of diagnostic criteria could partly explain this difference. Veldman criteria and Budapest Diagnostic Criteria were used in the two studies. The incidence of CRPS1 is greatly affected by the diagnostic criteria of CRPS1.The results of Annemerle Beerthuizen et al. [10] indicate that Budapest criteria are recommended in future studies on CRPS1. In fact, diagnosing CRPS I remains challenging in the absence of a uniform criterion standard. Another possible explanation of this lower incidence is the difference in fracture types. Our studies only included scaphoid waist fracture patients. Previous studies [10] have reported that intra-articular fracture patients seem to have a higher chance of developing CRPS1.

In our study, no significant difference was observed in wrist function of two groups, which could be partly 
Table 3 Logistic regression for variables predictive factors of occurrence of CRPS I

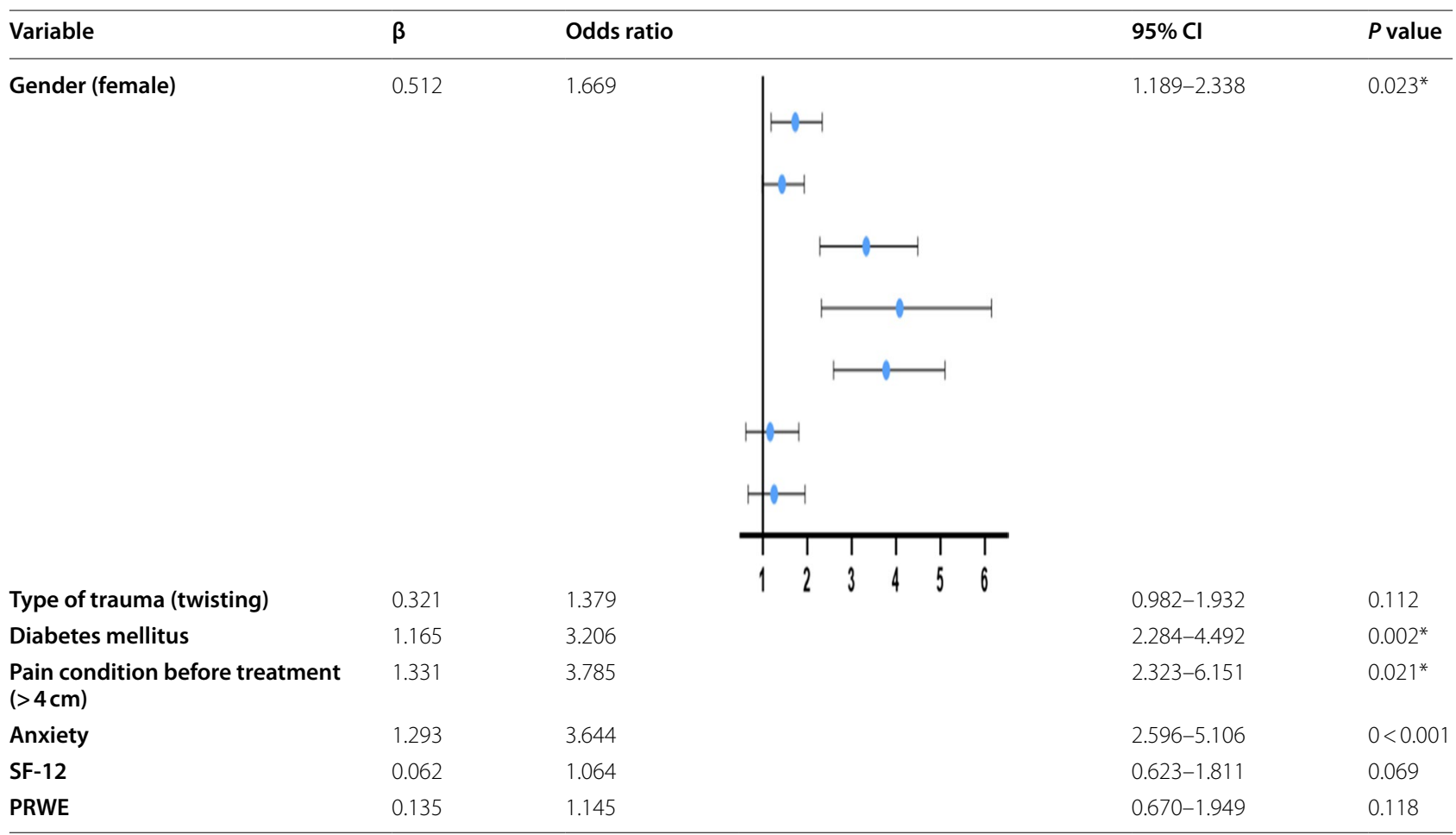

Multivariable logistic analysis was used, ${ }^{*} P<0.05$

$P R W E$ Patient-rated wrist evaluation score

explained by the characteristics of the disease. CRPS is a syndrome characterized by a continuing regional pain which is seemingly disproportionate in time or severity to the trauma events [4]. In this study, the statistically significant results of anxiety and mental aspect of SF12 were observed. High preoperative anxiety levels have been verified as a predictive index of the CRPS I following total knee arthroplasty [27]. Female sex, diabetes mellitus, and severe pain condition before treatment were independent risk factors for the development of CRPS I. Female sex has been identified as the risk factors for CRPS I by many studies [28-31]. Previous studies reported that CRPS I seems to be more prevalent in women, and the incidence of women was of 2-4 times that of men [28-31]. Women, especially postmenopausal women, have low vitamin D levels. Vitamin D deficiency is related to neuropathic pain. Sang-Uk Lee et al. [32] reported that the reason why the women's incidence of CRPS I is higher than men's may be that neuropathic pain is associated with the low vitamin $\mathrm{D}$ levels frequently found in post-menopausal women. Yesil et al. [33] reported that rheumatoid arthritis patients with serum vitamin D levels below $20 \mathrm{ng} / \mathrm{mL}$ exhibit an increased prevalence of neuropathic pain compared with patients with vitamin D values $30 \mathrm{ng} /$
$\mathrm{mL}$ or over (5.8:1). Therefore, early screening of pain conditions is vital for female patients.

In our study, diabetes mellitus was independently associated with CRPS I. Many studies have reported that diabetes mellitus is highly related to CRPS occurrence [34, 35]. Pro-inflammatory cytokines, including interleukin $-1 \beta$, interleukin- 6 and tumor necrosis factor-alpha, play an important role in the relationship of diabetes mellitus and CRPS I. Skin biopsy results show that the expression of pro-inflammatory cytokines was significantly higher in the upper extremities of CRPS-affected patients than in those of the unaffected patients [36, 37]. Pro-inflammatory cytokines which was derived from fat cells could lead to the resistance to insulin, while excessive fat cells promote the synthesis and secretion of pro-inflammatory cytokines [38]. In addition, Jong Ho Choi et al. [39] verified that higher HbA1c could be related to higher CRPS prevalence and that uncontrolled blood glucose could increase CRPS occurrence. Among the treatment of CRPS, it has always been a controversial issue whether physical therapy has a role for improving the clinical condition [40]. Diabetes mellitus was the risk factor of CRPS I. Our team believed that appropriate physical therapy can produce certain positive role in the prevention of CRPS I by decreasing the blood glucose [38]. 
In our study, a severe pain condition before treatment was also a risk factor for the development of CRPS I, which was almost identical to previous studies [10, 41] as reported by Barbara et al. [41] that reported that basal pain sensitivity and modulation vary widely in different patients. The sensitization of the nervous system could partly explain this phenomenon $[42,43]$. Therefore, the baseline pain condition of fractures deserves more attention.

There are some potential limitations that should be considered. First, the assessment of psychological conditions (anxiety and depression) is controversial because the HADS is a screening tool rather than a clinical diagnostic tool. Second, convenient sampling was used as the sampling method in this study, which could result in a large random error in the estimated prevalence ratio. Third, the small sample size could reduce the generalizability of this study.

\section{Conclusions}

Patients suffering from scaphoid waist fracture may be at a higher risk of CRPS I, especially in women with diabetes mellitus who report severe pain before treatment. Early screening and regular follow up evaluation are recommended in these patients.

\begin{abstract}
Abbreviations
CRPS I: Complex regional pain syndrome type I; OR: Odds Ratios; VAS: Visual analog scale; PRWE: Patient-rated wrist evaluation score; Cl: Confidence interval; QuickDASH: Quick Disabilities of the Arm, Shoulder, and Hand; SF-12: Short-Form Health Survey; HADS: Hospital Anxiety and Depression Scale.
\end{abstract}

\section{Acknowledgements}

The authors are grateful to all participants who willingly participated in their study and their biostatistics department.

\section{Authors' contributions}

(I) Conception and design: HG, GZ. (II) Administrative support: YL, ZL. (III) Provision of study materials or patients: HG, ZL. (IV) Collection and assembly of data: GZ, YL, (V) Data analysis and interpretation: HG, YL, ZL, (VI) Manuscript writing: All authors, (VII) Final approval of manuscript: All authors. All authors have read and approved the manuscript", and ensure that this is the case.

\section{Funding}

There is no funding source.

\section{Availability of data and materials}

All of the materials were provided by the Wuxi No.9 People's Hospital Affiliated to Soochow University, The datasets used and/or analyzed during the current study available from the corresponding author on reasonable request.

\section{Declarations}

\section{Ethics approval and consent to participate}

The authors are accountable for all aspects of the work in ensuring that questions related tothe accuracy or integrity of any part of the work are appropriately investigated and resolved.This study complied with the Declaration of Helsinki and was approved by EthicsCommittees of the Wuxi No.9 People's Hospital. Except for illiterate patients,all patients provided written informed consent. Illiterate patients indicate their consent by "making their mark** on the consent form, which were consistent with the local law and be approved by Ethics Committees of the Wuxi No.9 People's Hospital.

Consent for publication

Not applicable.

Competing interests

The authors declare that they have no conflict of interest.

\section{Author details}

${ }^{1}$ Department of Hand Surgery, Wuxi Ninth People's Hospital, Wuxi, Jiangsu,

China. ${ }^{2}$ Department of Medicine, Soochow University, Suzhou, China.

Received: 7 October 2021 Accepted: 20 December 2021

Published online: 05 January 2022

\section{References}

1. de Mos M, de Bruijn AGJ, Huygen FJPM, Dieleman JP, Stricker BHC, Sturkenboom MCJM. The incidence of complex regional pain syndrome: a population-based study. Pain. 2007;129(1-2):12-20. https://doi.org/10. 1016/j.pain.2006.09.008.

2. Sandroni P, Benrud-Larson LM, McClelland RL, Low PA. Complex regional pain syndrome type I: incidence and prevalence in Olmsted county, a population-based study. Pain. 2003;103(1-2):199-207. https://doi.org/10. 1016/s0304-3959(03)00065-4.

3. de Mos M, Sturkenboom MCJM, Huygen FJPM. Current understandings on complex regional pain syndrome. Pain Pract. 2009;9(2):86-99. https:// doi.org/10.1111/j.1533-2500.2009.00262.x.

4. Iolascon G, de Sire A, Moretti A, Gimigliano F. Complex regional pain syndrome (CRPS) type l: historical perspective and critical issues. Clin Cases Miner Bone Metab. 2015;12(Suppl:1. https://doi.org/10.11138/ccmbm/ 2015.12.3s.004.

5. Varenna M, Crotti C, Ughi N, Zucchi F, Caporali R. Determinants of diagnostic delay in complex regional pain syndrome type 1: an observational study of 180 consecutive new cases. J Clin Rheumatol. 2020. https://doi. org/10.1097/RHU.0000000000001558.

6. Moretti A, Palomba A, Paoletta M, Liguori S, Toro G, Iolascon G. Complex regional pain syndrome in athletes: scoping review. Medicina. 2021;57(11):1262. https://doi.org/10.3390/medicina57111262.

7. Iolascon G, Moretti A. Pharmacotherapeutic options for complex regional pain syndrome. Expert Opin Pharmacother. 2019;20(11):1377-86. https:// doi.org/10.1080/14656566.2019.1612367.

8. Israel D, Delclaux S, André A, Apredoaei C, Rongières M, Bonnevialle $P$, et al. Peri-lunate dislocation and fracture-dislocation of the wrist: retrospective evaluation of 65 cases. Orthop Traumatol Surg Res. 2016;102(3):351-5. https://doi.org/10.1016/j.otsr.2016.01.004.

9. Beltsios M, Savvidou OD, Kovanis J, Alexandropoulos P, Mitsiokapa EA, Mavrogenis AF, et al. Surgical outcome of scaphoid nonunions in heavy manual workers. J Surg Orthop Adv. 2010;19(4):209-13.

10. Beerthuizen A, Stronks DL, Van't Spijker A, Yaksh A, Hanraets BM, Klein J, et al. Demographic and medical parameters in the development of complex regional pain syndrome type 1 (CRPS1): prospective study on 596 patients with a fracture. Pain. 2012;153(6):1187-92. https://doi.org/ 10.1016/j.pain.2012.01.026.

11. Wells ME, Nicholson TC, Macias RA, Nesti LJ, Dunn JC. Incidence of scaphoid fractures and associated injuries at US trauma centers. J Wrist Surg. 2021;10(2):123-8. https://doi.org/10.1055/s-0040-1720963.

12. Johnson NA, Dias R, Dias JJ. Scaphoid alignment in dorsally displaced distal radial fracture: a radiographic study. J Hand Surg Eur. 2021;46(6):600-6. https://doi.org/10.1177/1753193420983696.

13. Dias JJ, Wildin CJ, Bhowal B, Thompson JR. Should acute scaphoid fractures be fixed? A randomized controlled trial. J Bone Joint Surg Am. 2005;87(10):2160-8. https://doi.org/10.2106/JBJS.D.02305.

14. Dias JJ, Brealey SD, Fairhurst C, Amirfeyz R, Bhowal B, Blewitt N, et al. Surgery versus cast immobilisation for adults with a bicortical fracture of the scaphoid waist (SWIFFT): a pragmatic, multicentre, open-label, randomised superiority trial. Lancet. 2020;396(10248):390-401. https:// doi.org/10.1016/S0140-6736(20)30931-4. 
15. Satteson ES, Harbour PW, Koman LA, Smith BP, Li Z. The risk of pain syndrome affecting a previously non-painful limb following trauma or surgery in patients with a history of complex regional pain syndrome. Scand J Pain. 2017;14:84-8. https://doi.org/10.1016/j.sjpain.2016.10.005.

16. Buijze GA, Goslings JC, Rhemrev SJ, Weening AA, Van Dijkman B, Doornberg JN, et al. Cast immobilization with and without immobilization of the thumb for nondisplaced and minimally displaced scaphoid waist fractures: a multicenter, randomized, controlled trial. J Hand Surg Am. 2014;39(4):621-7. https://doi.org/10.1016/j.jhsa.2013.12.039.

17. Hegazy G, Alshal E, Abdelaal M, Abdelaziz M, Moawad M, Saqr YM, et al. Kirschner wire versus Herbert screw fixation for the treatment of unstable scaphoid waist fracture nonunion using corticocancellous iliac bone graft: randomized clinical trial. Int Orthop. 2020;44(11):2385-93. https:// doi.org/10.1007/s00264-020-04730-7.

18. Harden NR, Bruehl S, Perez RSGM, Birklein F, Marinus J, Maihofner C, et al. Validation of proposed diagnostic criteria (the "Budapest criteria") for complex regional pain syndrome. Pain. 2010;150(2):268-74. https://doi. org/10.1016/j.pain.2010.04.030 Epub 2010 May 20.

19. Beaton DE, Wright JG, Katz JN. Development of the QUICKDASH: comparison of three item-reduction approaches. J Bone Joint Surg Am. 2005;87(5):1038. https://doi.org/10.2106/JBJS.D.02060.

20. Gummesson C, Ward MM, Atroshi I. The shortened disabilities of the arm, shoulder and hand questionnaire (QuickDASH): validity and reliability based on responses within the full-length DASH. Bmc Musculoskelet Disord. 7(1):44-0. https://doi.org/10.1186/1471-2474-7-44.

21. Cooney WP, Bussey R, Dobyns JH, Linscheid RL. Difficult wrist fractures. Perilunate fracture-dislocations of the wrist. Clin Orthop Relat Res. 1987;214:136-47.

22. Fan ZJ, Smith CK, Silverstein BA. Assessing validity of the QuickDASH and SF-12 as surveillance tools among workers with neck or upper extremity musculoskeletal disorders. J Hand Ther. 2008;21(4):354-65. https://doi. org/10.1197/j.jht.2008.02.001.

23. Julian LJ. Measures of anxiety: state-trait anxiety inventory (STAI), Beck anxiety inventory (BAI), and hospital anxiety and depression scale-anxiety (HADS-A). Arthritis Care Res. 2011;63(Suppl 11):S467-72. https://doi.org/ 10.1002/acr.20561.

24. van Smeden M, Moons KG, de Groot JA, Collins GS, Altman DG, Eijkemans MJ, et al. Sample size for binary logistic prediction models: beyond events per variable criteria. Stat Methods Med Res. 2019;28(8):2455-74. https:// doi.org/10.1177/0962280218784726.

25. Ten Brink AF, Bultitude JH. Predictors of self-reported neglect-like symptoms and involuntary movements in complex regional pain syndrome compared to other chronic limb pain conditions. Pain Med. 2021;22(10):2337-49. https://doi.org/10.1093/pm/pnab226.

26. Jellad A, Salah S, Frih BS, Z. Complex regional pain syndrome type I: incidence and risk factors in patients with fracture of the distal radius. Arch Phys Med Rehabil. 2014;95(3):487-92. https://doi.org/10.1016/j.apmr. 2013.09.012.

27. Harden NR, BruehI S, Stanos S, Brander V, Chung OY, Saltz S, et al. Prospective examination of pain-related and psychological predictors of CRPSlike phenomena following total knee arthroplasty: a preliminary study. Pain. 2003;106(3):393-400. https://doi.org/10.1016/j.pain.2003.08.009.

28. Ott S, Maihöfner C. Signs and symptoms in 1,043 patients with complex regional pain syndrome. J Pain. 2018;19(6):599-611. https://doi.org/10. 1016/j.jpain.2018.01.004.

29. Jo Y-H, Kim K, Lee B-G, Kim J-H, Lee C-H, Lee K-H. Incidence of and risk factors for complex regional pain syndrome type 1 after surgery for distal radius fractures: a population-based study. Sci Rep. 2019;9(1):4871. https://doi.org/10.1038/s41598-019-41152-x.

30. Elsharydah A, Loo NH, Minhajuddin A, Kandil ES. Complex regional pain syndrome type 1 predictors - epidemiological perspective from a national database analysis. J Clin Anesth. 2017;39:34-7. https://doi.org/10. 1016/j.jclinane.2017.03.027.

31. Elsamadicy AA, Yang S, Sergesketter AR, Ashraf B, Charalambous L, Kemeny $\mathrm{H}$, et al. Prevalence and cost analysis of complex regional pain syndrome (CRPS): a role for Neuromodulation. Neuromodulation. 2018;21(5):423-30. https://doi.org/10.1111/ner.12691.

32. Lee S-U, Na K-T, Lee Y-M, Park JH, Joo SY. Low vitamin D levels in post-menopausal women are associated with complex regional pain syndrome type I in surgically treated distal radius fractures. J Orthop Surg Res. 2020;15(1):328. https://doi.org/10.1186/s13018-020-01859-4.
33. Yesil H, Sungur U, Akdeniz S, Gurer G, Yalcın B, Dundar U. Association between serum vitamin D levels and neuropathic pain in rheumatoid arthritis patients: a cross-sectional study. Int J Rheum Dis. 2018;21(2):4319. https://doi.org/10.1111/1756-185X.13160.

34. Marshall AT, Crisp AJ. Reflex sympathetic dystrophy. Rheumatology (Oxford). 2000;39(7):692-5. https://doi.org/10.1093/rheumatology/39.7. 692.

35. Kim RP. The musculoskeletal complications of diabetes. Curr Diab Rep. 2002;2(1):49-52. https://doi.org/10.1007/s11892-002-0057-7.

36. Huygen FJPM, Ramdhani N, van Toorenenbergen A, Klein J, Zijlstra FJ. Mast cells are involved in inflammatory reactions during complex regional pain syndrome type 1. Immunol Lett. 2004;91(2-3):147-54. https://doi.org/10.1016/j.imlet.2003.11.013.

37. Groeneweg JG, Huygen FJPM, Heijmans-Antonissen C, Niehof S, Zijlstra FJ. Increased endothelin-1 and diminished nitric oxide levels in blister fluids of patients with intermediate cold type complex regional pain syndrome type 1. BMC Musculoskelet Disord. 2006;7:91. https://doi.org/10.1186/ 1471-2474-7-91.

38. Liu J, Zuo Q, Li Z, Chen J, Liu F. Trelagliptin ameliorates IL-1 $\beta$-impaired chondrocyte function via the AMPK/SOX-9 pathway. Mol Immunol. 2021;140:70-6. https://doi.org/10.1016/j.molimm.2021.09.009.

39. Choi JH, Yu KP, Yoon Y-S, Kim ES, Jeon JH. Relationship between HbA1c and complex regional pain syndrome in stroke patients with type 2 diabetes mellitus. Ann Rehabil Med. 2016;40(5):779-85. https://doi.org/ 10.5535/arm.2016.40.5.779.

40. Moretti A, Gimigliano F, Paoletta M, Liguori S, Toro G, Aulicino M, et al. Efficacy and effectiveness of physica1 agent moda1 ities in comp1eicregiona1 pain syndrome type i a scoping review. Appl Sci. 1857;2021:11.

41. Hastie BA, Riley JL, Robinson ME, Glover T, Campbell CM, Staud R, et al. Cluster analysis of multiple experimental pain modalities. Pain. 2005;116(3):227-37. https://doi.org/10.1016/j.pain.2005.04.016.

42. Perez RS, Zollinger PE, Dijkstra PU, Thomassen-Hilgersom IL, Zuurmond WW, Rosenbrand KC, et al. Evidence based guidelines for complex regional pain syndrome type 1. BMC Neurol. 2010;10:20. https://doi.org/ 10.1186/1471-2377-10-20.

43. Martini ML, Caridi JM, Zeldin L, Neifert SN, Nistal DA, Kim JD, et al. Perioperative outcomes of spinal cord stimulator placement in patients with complex regional pain syndrome compared with patients without complex regional pain syndrome. World Neurosurg. 2020;137:e106-17. https://doi.org/10.1016/j.wneu.2020.01.061.

\section{Publisher's Note}

Springer Nature remains neutral with regard to jurisdictional claims in published maps and institutional affiliations.

\footnotetext{
Ready to submit your research? Choose BMC and benefit from:

- fast, convenient online submission

- thorough peer review by experienced researchers in your field

- rapid publication on acceptance

- support for research data, including large and complex data types

- gold Open Access which fosters wider collaboration and increased citations

- maximum visibility for your research: over $100 \mathrm{M}$ website views per year
}

At BMC, research is always in progress.

Learn more biomedcentral.com/submissions 